\title{
Association between family history and essential hypertension in Han population in Shanghai China
}

li anle ( $\square$ anle_li@aliyun.com )

Jiading District Center for Disease Control and Prevention https://orcid.org/0000-0003-3200-4770

\section{Qian Peng}

Jiading District Center for Disease Control and Prevention

\section{Yue Qin Shao}

Jiading District Center for Disease Control and Prevention

\section{Yi Ying Zhang}

Jiading District Center for Disease Control and Prevention

\section{Fang Xiang}

Jiading District Center for Disease Control and Prevention

\section{Research article}

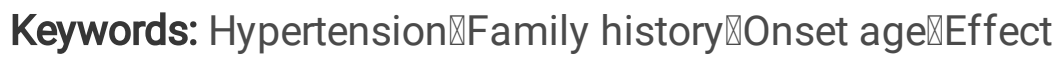

Posted Date: October 2nd, 2019

DOI: https://doi.org/10.21203/rs.2.11431/v2

License: (c) (i) This work is licensed under a Creative Commons Attribution 4.0 International License. Read Full License 


\section{Abstract}

Backgrounds Genetic factor is one of important influencing factors of essential hypertension, and family history $(\mathrm{FH})$ is an important marker of genetic factors. Objective To explore the association between family history and essential hypertension in Han population in Shanghai China.Methods The method of casecontrol study was used,342 cases of hypertension and 342 controls were selected and investigate their nuclear family members in the both study groups. The diagnostic information of hypertension in all relatives of these two groups was investigated. The method of genetic epidemiology research was used to explore the effect of family history.Results The average prevalence of hypertension was $23.32 \%$. The prevalence of hypertension of first-degree relatives was $33.99 \%$; the prevalence of second- degree relatives was $17.60 \%$; the prevalence of third-degree relatives was $13.51 \%$. All prevalence of hypertension of case group relatives was significantly higher than that of control group relatives. The average onset age in population with positive $\mathrm{FH}$ is $48.74 \pm 11.16$ years old, and the average onset age in population with negative $\mathrm{FH}$ is $54.38 \pm 9.87$ years old. The difference about two $\mathrm{FH}$ groups showed statistically significant $(t=4.589, P<0.001)$. The average onset age of offspring with father, mother, grandpa, grandma, maternal grandpa or maternal grandma positive was respectively $48.42,49.16,39.55,39.88,43.67$ or 43.64 years old; and the average onset age of children with father, mother, grandpa, grandma, maternal grandpa or maternal grandma negative was respectively $51.90,51.17,51.07,51.08,50.50$ or 50.57 years old. The difference about two groups showed statistically significant.Conclusion Family history had a positive effect on the occurrence of hypertension, and lead to earlier age of onset of offspring. The effects were different among parent and grandparent in Han in Shanghai China.

\section{Introduction}

Essential hypertension (EH) is a multifactorial disease caused by genetic factors and environmental exposed factors. Some studies suggested that there were two major factors affecting the incidence of hypertension: one was the genetic factor; the other was environmental exposed factors [1-11]. The interaction of genetic factors and some different exposed factors lead to different risk rate of populations or individuals suffering from the hypertension. It's well known that hypertension was a disease influenced by genetic factors, some studies showed that the effects of genetic factors on hypertension were about $20 \% \sim 55 \%$ [12-14], and there were many studies on genes or chromosomal loci that were linked to hypertension, but the results were controversial [15-22]. This difference was probably due to the small sample size of single study and the different source of the population. The effect of genetic factors on the occurrence of hypertension needs to be studied in more areas and more people.

It's believed that the genetic factor of hypertension was made up of a number of pathogenic genes that had a small but cumulative effect. But so far, the susceptibility genes for hypertension have not been finalized. The challenges of finding essential hypertension genes mainly might be genetic heterogeneity and effects from confounding factors, because of population stratification. The genes associated with essential hypertension might be a group and micro effect mode, each of which played a different role in different stages of the formation and development of hypertension and interacts with each other. The 
interaction between genes and genes, genes and environment exposed factors lead to different risk rate of hypertension among different populations and individuals. By the dose effect relationship of quantitative characters, the critical threshold of the occurrence of the disease was reached, and the genetic susceptibility to essential hypertension was determined simultaneously. Family history (FH) is an important marker of genetic factor; there are few reports on the effect of family history on hypertension alone.

This study used methods of genetic epidemiology study, based on the investigation of the essential hypertension cases family and the control family, to explore the association between family history and the onset age of essential hypertension in Han in Shanghai China.

\section{Methods}

\section{Determination of the cases group}

All cases were randomly selected from hypertension registry and follow-up management system, the diagnosis of blood pressure was based on outpatient or inpatient diagnosis in clinical hospitals. The diagnosis of hypertension was based on outpatient or inpatient diagnosis (the clinic blood pressure) in clinical hospitals. All cases were confirmed by hospital and verified by follow-up in the community, and they were able to correctly respond to the investigators for health information of themselves and their nuclear family members. Each case gave informed consent to participate in the study which was approved by the local ethics committee (JD-2016-KY-18).

\section{Determination of the controls group}

According to I:I matched pairs design, all controls population had no hypertension, and the control was required the same sex as the case, and the same race, living in the same community, and the difference of age was not more than 5 years old or at the same age group as the case. Each control gave informed consent to participate in the study. They were able to correctly respond to the investigators for the health information of themselves and their nuclear family members.

\section{Standard of case diagnosis and inclusion}

All cases were over 18 years old, who has been diagnosed by the hospital as essential hypertension, excluding secondary hypertension, such as renal artery stenosis, pheochromocytoma, hyperaldosteronism and other diseases.

\section{Family survey method and content}

All investigators were trained public health doctors, using a self-designed and unified questionnaire for the hereditary family of essential hypertension. Questionnaires were completed by direct inquiry including, the investigate contents include: age, sex, race, age of onset, diagnosis time, hospital name, family members and so on. The family investigation mainly includes: spouses, parents, siblings, children, uncle, aunt and 
cousin. The criteria for judging whether all the respondents had essential hypertension (all relatives of the case and the control population): whether they had been diagnosed with essential hypertension in the hospital before this investigation. If they had been diagnosed with essential hypertension in the hospital, it is "Yes"; if they had not been diagnosed, it is "No".

\section{Statistical analysis method}

Statistical analyses were performed using the statistical software package (IBM SPSS statistics version 21). Case-control study and genetic epidemiological data analysis were used to analyze the differences between the two groups and the variations among different family histories [23]. The comparison of counting data was examined by Chi-square test, and the comparison of measurement data was examined by $\boldsymbol{t}$ test. When $\mathrm{P}$ values $<0.05$, the difference is considered statistically significant.

\section{Results}

\section{Characteristics of population}

In this study, 342 (male 171, female 171) precursor cases and 342 (male 169, female 173) control population were investigated, average age in the case group was $62.4 \pm 10.7$ years old, and average age in the control group was $61.7 \pm 10.7$ years old. Among these investigated people, they are all Han races, so racial analysis was no further conducted again. The difference of age and sex between case group and control group were not significant ( $\mathrm{t}_{\mathrm{age}}=0.894, \mathrm{p}_{\mathrm{age}}=0.372 ; \mathrm{x}^{2}$ sex $=0.119, \mathrm{p}_{\mathrm{sex}}=0.730$ ). Total number of nuclear family members investigated was 8814 (4454 in case group, 4360 in control group), and the average nuclear family member was 12.88 (case group is 13.02 ; control group is 12.74 ).

Among 4104 investigated population in the elder member of a family (include father, mother, grandpa, grandma, maternal grandpa and maternal grandma), there were 839 relatives were definitely diagnosed with hypertension. The prevalence of hypertension was $20.44 \%$ in the elder relatives of this investigation. Among 3265 non-hypertensive relatives, there may also be some patients with potential or recessive hypertension who have not been clearly diagnosed. There is no reverse effect on the results of this study, so no further discussion will be conducted.

\section{Family history}

There were 2055 hypertensive patient has been clearly diagnosed in the hospital among this investigated population in this study, the average prevalence was $23.32 \%$. The prevalence rate of hypertension of firstdegree relatives was $33.99 \%$; prevalence rate of second- degree relatives was $17.60 \%$; prevalence rate of third-degree relatives was $13.51 \%$. This result showed that the order of hypertension prevalence rate was as follows: first-degree relatives > second- degree relatives > third-degree relatives.

All prevalence rates of hypertension of case group relatives were significantly higher than that of control group relatives. The result showed a phenomenon of familial aggregation in the distribution of hypertension. See tab1. 
Among these family members and relatives in case and control group, there were 575 hypertension in parent population, the prevalence was $42.03 \%$; 549 in sibling population, the prevalence was $39.96 \% ; 100$ in offspring population, the average prevalence was $11.64 \% ; 291$ in paternal siblings population (brother and sister of father), the prevalence was $18.27 \%$; 255 in maternal siblings population ( brother and sister of mother), the prevalence was $16.89 \%$; 46 in paternal cousin population, the prevalence was $13.11 \% ; 239$ in maternal cousin population, the prevalence was $13.59 \%$. The difference of hypertension prevalence in three degree relative populations between case group and control group were significant. See table 1 .

Among 4104 investigated population in the elder member of 684 families (include father, mother, grandpa, grandma, maternal grandpa and maternal grandma), there were 575 hypertension cases in parent population (include father and mother), the prevalence of parent was $42.03 \%$; and 89 hypertension cases in grandparent population (include grandpa and grandma), the prevalence of grandparent was $6.51 \%$; and 69 hypertension cases in maternal grandparent population (include maternal grandpa and maternal grandma), the prevalence of maternal grandparent was $5.04 \%$. Because most of the grandparents and maternal grandparents have been died before this investigation, a large number of hypertension cases may be omitted because of unknown or not diagnosed in the retrospective investigation, resulting in the low prevalence of these two groups of population. See table 2.

Table 1: The hypertension prevalence rate (\%) of relatives in case and control group

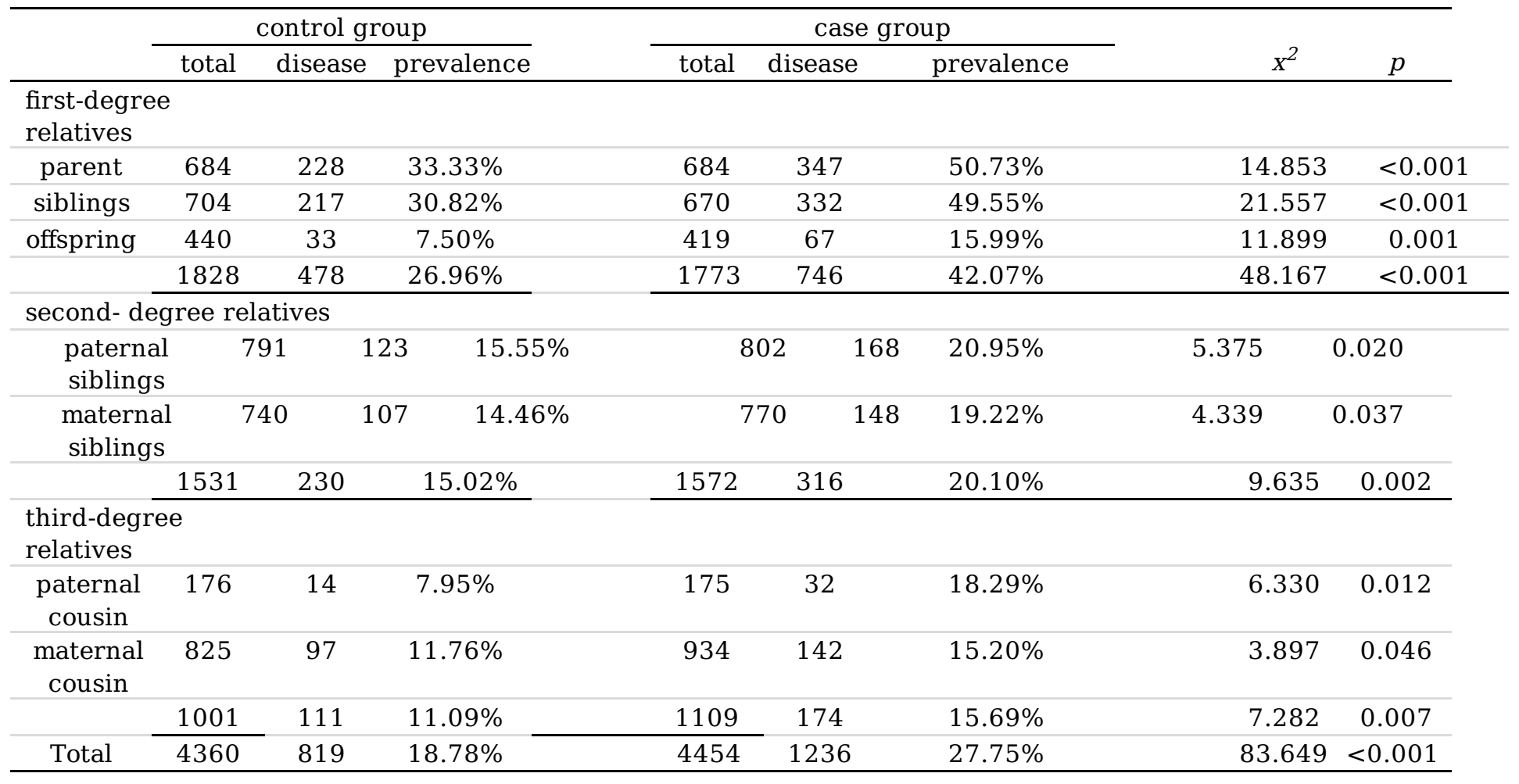

Note: "total" was the number of people investigated, "disease" was number of hypertension, "prevalence "="disease / total $* 100 \% ; x^{2}$ and $p$ value were calculated by $x^{2}$ test. 
Table 2: The hypertension prevalence rate (\%) of elder member in case and control group

\begin{tabular}{|c|c|c|c|c|c|c|c|c|}
\hline \multicolumn{4}{|c|}{ Control group } & \multicolumn{3}{|c|}{ Case group } & \multirow[t]{2}{*}{$x^{2}$} & \multirow[t]{2}{*}{$p$} \\
\hline No & & Yes & $\%$ & No & Yes & $\%$ & & \\
\hline father & 222 & 120 & 35.08 & 170 & 172 & 50.32 & 16.158 & $<0.001$ \\
\hline mother & 234 & 108 & 31.48 & 167 & 175 & 51.29 & 27.057 & $<0.001$ \\
\hline grandpa & 323 & 19 & 5.57 & 311 & 31 & 9.03 & 3.107 & 0.078 \\
\hline grandma & 323 & 19 & 5.57 & 322 & 20 & 5.81 & 0.027 & 0.869 \\
\hline maternal grandpa & 331 & 11 & 3.28 & 324 & 18 & 5.16 & 1.764 & 0.184 \\
\hline maternal grandma & 324 & 18 & 5.25 & 320 & 22 & 6.45 & 0.426 & 0.514 \\
\hline
\end{tabular}

Note: "No" was number of non-hypertension, "Yes" was number of hypertension, $\mathrm{x}^{2}$ and $\mathrm{p}$ value were calculated by $\boldsymbol{x}^{2}$ test.

\section{FH affects onset age of hypertension}

If one or more relatives of the first-degree relatives (include father, mother, grandpa, grandma, maternal grandpa and maternal grandma) have been definitely diagnosed with hypertension, family history (FH) is called positive, otherwise is called negative. Among 342 cases in the case group, the result showed that the average onset age in population with positive $\mathrm{FH}$ is $48.74(48.74 \pm 11.16)$ years old, and the average

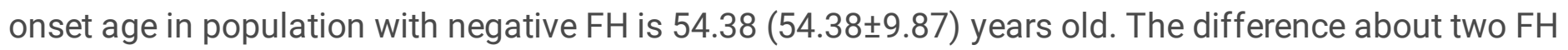
groups showed statistically significant $(t=4.589, P<0.001)$. Among the first-degree relatives, the efficacy on the age of onset of hypertension in offspring is different for different relatives. See table3.

Table 3 showed that either parents or grandparents or maternal grandparents in the first-degree relatives could affect the onset age of hypertension of children, it's just that the level of effect was different. Grandpa and grandma are particularly influential among the first-degree relatives. The average onset age of children with grandpa or grandma positive was respectively $39.55(39.55 \pm 11.95)$ or 39.88 $(39.88 \pm 11.90)$ years old; and the average onset age of children with grandpa or grandma negative was respectively $51.07(51.07 \pm 10.59)$ or $51.08(51.08 \pm 10.60)$ years old. The difference about two groups showed statistically significant (see table3). The results suggest that the onset age of hypertension of children with grandpa or grandma positive was about 11 years earlier likely than that of children grandpa or grandma negative.

Table 3: The average onset age of hypertension in case group with different family history 


\begin{tabular}{|c|c|c|c|c|c|c|}
\hline & \multirow[t]{2}{*}{ Hypertension } & \multirow[t]{2}{*}{$\mathrm{N}$} & \multicolumn{2}{|c|}{ Onset age (y) } & \multirow[t]{2}{*}{$t$} & \multirow[t]{2}{*}{$p$} \\
\hline & & & mean & $\mathrm{SD}$ & & \\
\hline \multirow[t]{2}{*}{ father } & Yes & 167 & 48.42 & 11.16 & 3.194 & 0.002 \\
\hline & No & 175 & 51.90 & 10.81 & & \\
\hline \multirow[t]{2}{*}{ mother } & Yes & 166 & 49.16 & 11.12 & 1.832 & 0.068 \\
\hline & No & 176 & 51.17 & 11.04 & & \\
\hline \multirow[t]{2}{*}{ grandpa } & Yes & 26 & 39.55 & 11.95 & 5.768 & $<0.001$ \\
\hline & No & 316 & 51.07 & 10.59 & & \\
\hline \multirow[t]{2}{*}{ grandma } & Yes & 27 & 39.88 & 11.90 & 5.682 & $<0.001$ \\
\hline & No & 315 & 51.08 & 10.60 & & \\
\hline \multirow[t]{2}{*}{ maternal grandpa } & Yes & 15 & 43.67 & 9.77 & 2.883 & 0.010 \\
\hline & No & 327 & 50.50 & 11.09 & & \\
\hline \multirow[t]{2}{*}{ maternal grandma } & Yes & 18 & 43.64 & 10.21 & 3.086 & 0.005 \\
\hline & No & 324 & 50.57 & 11.06 & & \\
\hline
\end{tabular}

Note: "N" was the number of people, "mean" and "SD" were the mean and standard deviation of onset age, t and $p$ value were calculated by $\boldsymbol{t}$ test.

\section{Discussion}

Clinically, hypertension can be divided into two categories: one is essential hypertension, it's an independent disease with elevated blood pressure as its main clinical manifestation and unclear etiology, accounting for more than $90 \%$ of all hypertensive patients; the other is secondary hypertension, also known as symptomatic hypertension, it has a clear etiology, and it mainly caused by renal artery stenosis, pheochromocytoma, hyperaldosteronism and other diseases. This study mainly studied the influence of family history on hypertension, in order to exclude the interference of other factors, it was necessary to exclude secondary hypertension and only study primary hypertension. Therefore, in the case selection of design stage in this study, only primary hypertension was selected.

It's well known that the genetic factors play an important basic role in the occurrence of hypertension, and family history is a sign reflecting the main role of genetic factors. It's showed that family history plays an important role in the development of hypertension through interaction with acquired risk factors such as body mass index (BMI), and the interaction of family history and $\mathrm{BMI}$ is greater than the sum of two independent actions [24-28]. In this study, the genetic epidemiological results showed that the prevalence of hypertension in three degree relatives was different. The prevalence in the first degree relatives (including parents, siblings and offspring) was the highest (33.99\%), the prevalence in the second degree relatives (including paternal siblings and maternal siblings) was the next $(17.60 \%)$, and the prevalence in the third degree relatives (including paternal cousin and maternal cousin) was lowest (13.51\%). The difference of hypertension prevalence among three degree relatives in Han in Shanghai China were significantly $(P<0.05)$. All prevalence rates of three degree relatives of case group relatives were significantly higher than that of control group relatives. It was suggested that genetic factors have obvious influence on the occurrence of essential hypertension, and the genetic potency may be decrease with the increase of degree relatives. 
Among 684 families, the prevalence of parent population (include father and mother) was high (42.03\%), and the prevalence of case group relatives were significantly higher than that of control group relatives. The prevalence of grandparent population (include grandpa and grandma) or maternal grandparent population (include maternal grandpa and maternal grandma) was lower, and the difference of prevalence between case group and control group. Owing to most of the grandparents and maternal grandparents have been died before investigation, a large number of hypertension cases may be omitted because of unknown or not diagnosed in the retrospective investigation, resulting in the low prevalence of these two groups of population. If we update the data collection methods and increase the sample size in future studies, we may be able to find differences between the two groups.

Some studies showed that the heritability of hypertension was 20\% 55\% [12-14]. it indicated that there were also ethnic differences in hypertension susceptibility genes among different ethnic groups. In order to further quantitatively assess the impact of family history on hypertension, we chose age of onset as an indicator. In this study, the result showed that the average onset age in population with positive $\mathrm{FH}$ is 48.74 years old, and the average onset age in population with negative $\mathrm{FH}$ is 54.38 years old, the difference about two FH groups showed statistically significant. The average onset age of hypertension in cases with positive family history is likely 5 years earlier than that of cases with negative family history. The efficacy on the age of onset of hypertension in offspring is different for different relatives. The average onset age of children with father or mother positive was respectively 48.42 or 49.16 years old; and the average onset age of children with grandpa or grandma negative was respectively 51.90 or 51.17 years old. The average onset age of hypertension in cases with positive parents is likely 2-3 years earlier than that of cases with negative parents. The average onset age of children with grandpa or grandma positive was respectively 39.55 or 39.88 years old; and the average onset age of children with grandpa or grandma negative was respectively 51.07 or 51.08 years old, the average onset age of hypertension in cases with positive grandparents is likely 11 years earlier than that of cases with negative grandparents. The average onset age of children with maternal grandpa or grandma positive was respectively 43.67 or 43.64 years old; and the average onset age of children with maternal grandpa or grandma negative was respectively 50.50 or 50.57 years old, the average onset age of hypertension in cases with positive maternal grandparents is likely 7 years earlier than that of cases with negative maternal grandparents.

\section{Conclusion}

Family history has a positive effect on the occurrence of hypertension, and lead to earlier age of onset of offspring. The effects are different among parent and grandparent in Han in Shanghai China.

\section{Declarations}

\section{Ethics approval and consent to participate}

Ethical approval was granted by Jiading district center for disease control and prevention research ethics committee (JD-2016-KY-18). All subjects gave informed consent to participate in the study, they would like to participate in investigation and answer all the related questions in the questionnaire. 


\section{Consent for publication}

Not applicable.

\section{Availability of data and material}

The questionnaire and database supporting the conclusions of this article are available, through contact with anle_li@aliyun.com.

\section{Competing interests}

The authors declare that they have no competing interests.

\section{Funding}

This study was funded by Jiading district health and family planning commission research project in Shanghai $\mathbb{N} 0 \otimes 2016-K Y-18 \rrbracket$

\section{Authors' contributions}

The original idea for the project was conceived by An-le LI. Qian Peng囚Yue-qin Shao, Yi-ying Zhang, Xiang Fang participated in the collection of early data, quality control, and gave a lot of administrative support. LI An-le conceptualized the paper, analyzed data and wrote a first draft of the manuscript. All authors contributed to subsequent drafts and approved the final manuscript.

\section{Acknowledgements}

Heartfelt thanks to all doctors, nurses and public health workers in 13 community health service centers in Jiading district in Shanghai for their hard work. Thank for some advice of the experts!

\section{References}

1. Aune D, Sen A, Norat T, et al. Body Mass Index, Abdominal Fatness, and Heart Failure Incidence and Mortality: A Systematic Review and Dose-Response Meta-Analysis of Prospective Studies[J]. Circulation,2016, 133(7): 639-649.

2. Modesti P. A., Agostoni P., Agyemang C., et al. Cardiovascular risk assessment in low-resource settings: a consensus document of the European Society of Hypertension Working Group on Hypertension and Cardiovascular Risk in Low Resource Settings. Journal of Hypertension. 2014;32(5):951-960.

3. Kotchen T. A. Obesity-related hypertension: epidemiology, pathophysiology, and clinical management. American Journal of Hypertension. 2010;23(11):1170-1178.

4. Biino G, Parati G, Concas MP, Adamo M, Angius A, Vaccargiu S, Pirastu M. Environmental and genetic contribution to hypertension prevalence:data from an epidemiological survey on Sardinian genetic isolates. PLoS One. 2013;8:e59612. doi: 10.1371/journal.pone.0059612. 
5. Echouffo-Tcheugui JB, Batty GD, Kivimäki M, Kengne AP. Risk models to predict hypertension: a systematic review. PLoS One. 2013;8:e67370.doi: 10.1371/journal.pone.0067370.

6. Gu D, Reynolds K, Wu X, Chen J, Duan X, Muntner P, Huang G, Reynolds RF, Su S, Whelton PK, He J; InterASIA Collaborative Group.The International Collaborative Study of Cardiovascular Disease in ASIA. Prevalence, awareness, treatment, and control of hypertension in china. Hypertension. 2002;40:920-927.

7. Izawa H, Yamada Y, Okada T, Tanaka M, Hirayama H, Yokota M. Prediction of genetic risk for hypertension. Hypertension. 2003;41:1035-1040.

8. Whelton PK, He J, Appel LJ, et al. Primary prevention of hypertension: clinical and public health

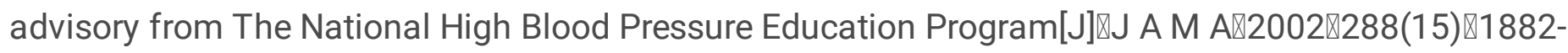
1888区

9. Kingsbury MA, Rehen SK, Contos JJ, Higgins CM, Chun J. Non-proliferative effects of lysophosphatidic acid enhance cortical growth and folding. Nature neuroscience. 2003;6: 1292-1299.

10. Zaw KK囚Latt TS $₫$ Aung PP囚et a1هPrevalence of hypertension and its associated factors in the adult

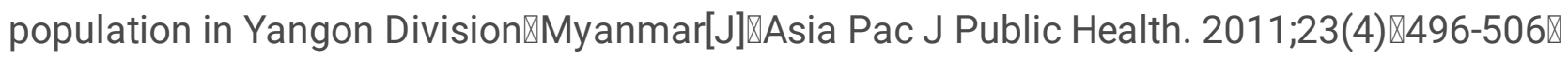

11. Contos JJ, Fukushima N, Weiner JA, Kaushal D, Chun J. Requirement for the Ipa 1 lysophosphatidic acid receptor gene in normal suckling behavior. Proceedings of the National Academy of Sciences of the United States of America. 2000;97:13384-13389.

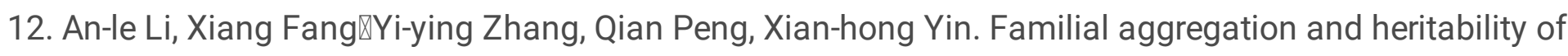
hypertension in Han population in Shanghai China: a case-control study[J]. BMC囚Clinical hypertension. 2019ه25囚17ه1-7.

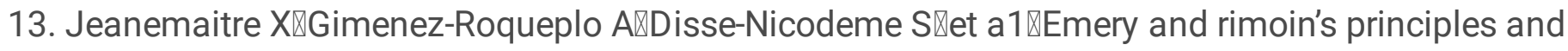
practice of medical genetics e-dition principles of medic $\mathrm{H}$ genetics $₫ 5$ th ed $囚$ philadelphia $₫ C h u r c h i l l$ lying-ston Elsevier $\ 2007 \rrbracket 283-330 \rrbracket$

14. Levy D囚Ehret GB囚Rice K囚et a1囚Genome-wide association study of blood pressure and hypertension[J]区Nat Genet $₫ 2009 ₫ 41(6) \llbracket 677-687 \rrbracket$

15. Rafiq S, Anand S, Roberts R. Genome-wide association studies of hypertension: have they been fruitful?[J]. Cardiovasc Transl Res. 2010;3(3):189-196.

16. International Consortium for Blood Pressure Genome-Wide Association Studies『Ehret GB囚Munroe PB囚 et a1囚Genetic variants in novel pathways influence blood pressure and cardiovascular disease risk[J]区 Nature $₫ 2011 \llbracket 478(7367) \otimes 103-109 \rrbracket$

17. Levy D『Ehret GB囚Rice K囚et a1囚Genome-wide association study of blood pressure and hypertension[J]区Nat Genet $₫ 2009 ₫ 41(6) \llbracket 677-687 \rrbracket$

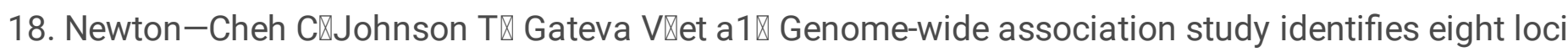

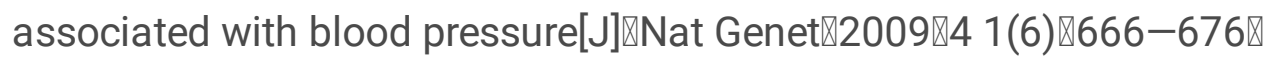

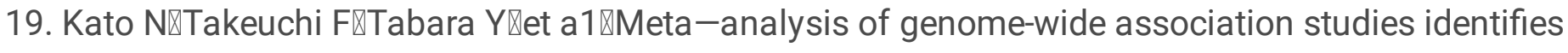
common variants associated with blood pressure variation in east Asians[J]区Nat Genet\201 1ه43(6)区 53 1-538ه 
20. Lahiri $D \otimes M a l o n e y ~ B \otimes G e n e s$ are not our destiny $₫$ the somaticepitype bridges between the genotype and

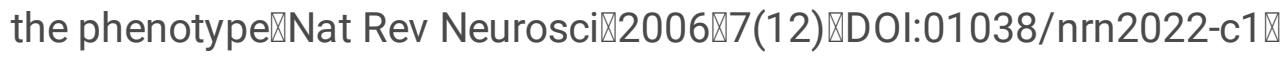

21. Uher R囚ne implications of gene-environmem interactions in depression $\llbracket$ will cause inform cure?Mol Psychiatry $₫ 2008 \rrbracket 13(12) \otimes 1070 \rrbracket 1078 \rrbracket$

22. Ehrel GB. Genome-Wide Association Studies $₫$ Contribution of Genomic to Understanding Blood Pressure and Essential Hypertension $\square J \mathbb{J}$. Curr Hypertens Report囚2010,12:17-25.

23. Zhongtang Zhao. Epidemiological Research Methods and Applications (2nd Edition) [B]. Science Press (Beijing). 2005.8: 223-241.

24. An-le Li, Qian Peng, Yue-qin Shao, Xiang Fang and Yi-ying Zhang. The effect of body mass index and its interaction with family history on hypertension: a case-control study [J]. BMC: Clinical Hypertension. 2019, 25(6): 1-8.

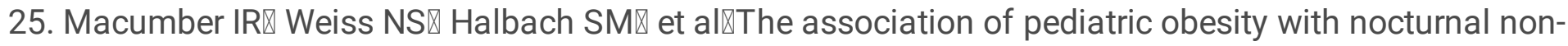
dipping on 24-hour ambulatory blood pressure monitoring [ J] $\varangle$ Am J Hypertens $\varangle 2016,29$ (5) : 647 $-652 \rrbracket$

26. Olack B, Wabwire-Mangen F, Smeeth $L$, et al『Risk factors of hypertension among adults aged 35-64 years living in an urban slum Nairobi, Kenya[J四 BMC Public Health, 2015囚15(1):1》

27. JOshi MD, Ayah R, Njau EK, et alهPrevalence of hypertension and associated cardiovascular risk

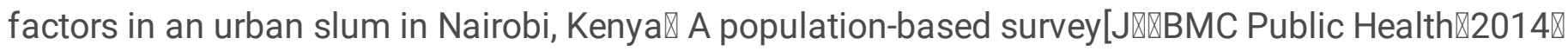
14(1) $ه 1 \otimes$

28. Aune D, Sen A, Norat T, et al. Body Mass Index, Abdominal Fatness, and Heart Failure Incidence and Mortality: A Systematic Review and Dose-Response Meta-Analysis of Prospective Studies [J]. Circulation,2016, 133(7): 639-649. 